\title{
The effectiveness of training given to nurses for reducing ventilator-associated pneumonia in intensive care patients
}

\author{
HATICE ONER CENGIZ ${ }^{*}$ and NEVIN KANAN ${ }^{2}$ \\ ${ }^{1}$ First and Emergency Programme, Vocational School of Health Services, KTO Karatay University, Konya, Turkey \\ ${ }^{2}$ Department of Surgical Diseases Nursing, Florence Nightingale Nursing Faculty, Istanbul University, Istanbul, Turkey
}

(Received: March 11, 2019; revised manuscript received: May 6, 2019; accepted: July 28, 2019)

\begin{abstract}
Purpose: The aim of this study it to determine the effect of training intensive care unit (ICU) nurses in reducing ventilator-associated pneumonia (VAP). Materials and methods: A quasi-experimental (single group, pre-testpost-test) model was used. The study was conducted in 2015, in nine adult ICUs in Istanbul, where we observed the VAP rate and trained study group nurses. Sixty nurses were given two VAP training sessions (averaging $45 \mathrm{~min}$ each) at intervals of 6 months. Forty-nine nurses were in the control group. Data were collected with an Introductory Information Form, a VAP Information Test, and an Application Status of VAP Preventive/Reducing Initiatives Form. The incidences of VAP in 2014 and 2015 were also compared. Frequencies, percentages, means, standard deviations, $t$-tests, Wilcoxon tests, and $\chi^{2}$ tests were used to evaluate the data. The values of $p$ less than .05 were considered significant. Results: The mean-total-knowledge score increased significantly in the study group. The application of preventive/reducing initiatives also increased significantly in the study group, but in the last measurement, the difference between the groups was not statistically significant. The incidences of VAP decreased significantly in the study group. Conclusion: The study showed that the VAP training given to intensive care nurses increased their knowledge level and decreased the incidence of VAP in their ICUs.
\end{abstract}

Keywords: education, infection control, nursing, ventilator-associated pneumonia, intensive care

\section{INTRODUCTION}

Ventilator-associated pneumonia (VAP) is pneumonia that occurs within $48 \mathrm{hr}$ after the intubation of intensive care patients [1-4]. Because the VAP rate depends on a number of factors, such as age, days of mechanical ventilation, and chronic diseases, the real incidence of VAP is difficult to determine [1], but in the literature [1, 3-5], it is considered to be high. In studies conducted in Egypt, Iran, China, the United States of America, and Turkey, the VAP rate per 1,000 mechanical ventilator days was found to be $70.3,21.08$, 29.5 (13.4 medical/surgical ICU and 23.7 medical ICU), and 31.2 , respectively [6-8]. The rate of mortality related to VAP is also high. For example, the mortality rate is $35.3 \%$ in Finland, $53 \%$ in Jordan, and $24.5 \%$ in Turkey $[5,9,10]$.

Although VAP has high morbidity and mortality rates, it is reported that these rates can be reduced by $20 \%$ with appropriate initiatives. These include the training of health workers, hand hygiene, semi-recumbent positioning $\left(30^{\circ}-45^{\circ}\right)$, use of chlorhexidine gluconate in oral care, aspiration of subglottic secretions, use of a closed aspiration system, monitoring of gastric residual volume, control of the endotracheal tube cuff pressure, and suitable replacement of ventilator circuits $[8,11,12]$. It is understood that most of the interventions to prevent VAP are closely related to nursing interventions. For this reason, it is emphasized that training health workers, especially nurses, in VAP interventions, and increasing their level of knowledge on this subject, play very important roles [13-15]. It is reported, however, that intensive care nurses have low-level or moderate awareness, knowledge, attitude, and harmony about evidence-based practices to prevent VAP [12, 16-20].

It is therefore important to train nurses on this subject and to repeat this training at certain intervals to reduce the VAP rate $[16,17,21]$. It has been shown that training given to intensive care nurses in VAP increased the level of knowledge and harmony in nurses, and thus reduced the VAP rate. Moreover, it has been reported that there is a great need for multicentered studies on this subject, and that an increase in the number of studies strengthens the effect of the care in reducing the VAP rate $[8,17,18,22,23]$.

In light of this information, when it was also considered that nurses in Turkey have different educational levels, and that there are many difficulties in the delivery of qualified care in Turkey, this study was conducted to determine the effect of the training given to nurses in reducing the VAP rate in adult ICU patients.

\footnotetext{
* Corresponding author: Asst. Prof. Hatice Oner Cengiz; First and Emergency Programme, Vocational School of Health Services, KTO Karatay University, Akabe District, Alaaddin Kap Street, No: 130 Karatay, Konya, Turkey; Phone: +90 554267 2908; E-mails: htcnr8878@gmail.com; hatice.oner.cengiz@karatay.edu.tr
}

This is an open-access article distributed under the terms of the Creative Commons Attribution-NonCommercial 4.0 International License, which permits unrestricted use, distribution, and reproduction in any medium for non-commercial purposes, provided the original author and source are credited, a link to the CC License is provided, and changes - if any - are indicated. 


\section{RESEARCH HYPOTHESES}

H1: The knowledge level of VAP in nurses with training will be higher than those without training.

H2: The application of preventive/reducing nursing initiatives for VAP in nurses with training will be higher than those without training.

H3: After VAP training is given to intensive care nurses, the rate of VAP in their ICUs will be lower than in ICUs with untrained nurses.

\section{MATERIALS AND METHODS}

\section{Design}

A quasi-experimental model (pre-test/post-test controlgroup design with non-randomized groups) was used in this study.

\section{Sample and settings}

The study was conducted in nine adult ICUs in five tertiarycare hospitals in Istanbul between January 1, 2015 and January 30, 2016. We aimed for at least 50 nurses in the study group and 50 nurses in the control group. The thirdlevel ICUs where the VAP rate was observed, permitting the conduct of the study, were included in the study. First and second level, paediatric and neonatal ICUs, and ICUs that do not allow the study are excluded. The ICUs were selected using a purposeful sampling method, considering the number of working nurses. We aimed to reach all the nurses in these ICUs, as it was thought the number of nurses might decrease. To reach the number of samples, more intensive care units (ICUs) were included in the study. Therefore, six ICUs were used for the study group and three for the control group. A total of 220 nurses were reached, but due to reasons such as maternity leave, military service, and leaving the institution, some of the nurses could not be included. The final number of participating nurses was 60 in the study group and 49 in the control group.

\section{Questionnaires}

The data were collected with an Introductory Information Form, a VAP Information Test, and an Application Status of VAP Preventive/Reducing Initiatives Form. The validity and reliability analyses of the data collection tools were carried out on the same group. A VAP Information Booklet and VAP Information Poster containing information about the training were prepared for the ICUs. The forms, booklet, and poster were prepared by the researchers in line with the literature [12, 20, 24-29]. All the forms were reviewed in the preparation phase by two anaesthetists and two nurses to evaluate the quality. A pilot implementation of the forms was administered to five ICU nurses working in different hospitals, independent of the study. The data of the nurses were collected by submitting these forms to the groups based on the structured self-report technique.

The Introductory Information Form consisted of 11 items and was developed to identify the descriptive characteristics of the nurses. The VAP Information Test consisted of 20 closed-ended questions including the definition of VAP, risk factors, signs and symptoms, and preventive/reducing treatment and care initiatives. In the study, when the discrimination power values of the items on the VAP Information Test were examined, this test was an adequate test that could be used to measure the knowledge of the nurses. The reliability of the test (KR21) was found to be as high as 0.774. The Application Status of VAP Preventive/Reducing Initiatives consisted of 14 items, including nonpharmacological initiatives. The list of the items was a Likert-type scale. Each initiative was rated as (0) Never implemented, (1) Rarely applied, (2) Sometimes implemented, (3) Mostly implemented, or (4) Always implemented. To be able to statistically compare the implementation status of the initiatives on the form in both the intragroup and intergroup, the mean of the total points was calculated. This scale was calculated as Never implemented - 0 points, Rarely applied - 1 point, Sometimes implemented 2 points, Mostly implemented -3 points, and Always implemented -4 points. Thus, the total score of the form was evaluated over the range of $0-56$ points. High total scores showed that VAP Preventive/Reducing Nursing Initiatives were applied at a high level. The value of Cronbach's $\alpha$ (internal consistency coefficient), which was used to calculate the reliability of the 14 items in this form, was detected to be 0.884 (satisfactory).

\section{Initiatives and data collection}

Nurses in the study group were interviewed and told that the training would be given only by the researchers. Two VAP training sessions were given at intervals of 6 months. During the follow-up period, each nurse who started to work in the nursing care unit was trained. These nurses were not included in the study, however, because they did not participate in all stages of the education.

The first training. The nurses filled out all the forms immediately before the start of the training. The training (averaging 45 min per session) was presented in the form of a Power-Point Presentation, given by the researcher in an interactive manner. After the training was completed, the nurses were asked to retake the VAP Information Test.

The second training. It was carried out 6 months after the first. The stages of the first training were repeated. Since it was possible to reach the ICU nurses in more than one training program, the information booklet was distributed after all the nurses were trained, and the informational posters were hung in working areas where the nurses could always see them. After the clinical orientation program was conducted for the nurses who had just begun to work in the ICU (approximately 1-1.5 months later), they were trained in the same way.

The last measurement. The nurses were asked to refill the questionnaires 6 months after the second training. Two hundred and twenty nurses were trained over the year, but only data on those who participated in all phases of the study (60 nurses) were used. No training was given to the control group, but the nurses filled out all the forms in January and December of 2015. Only data from those in the control group who completed the questionnaires twice were used. 
Since the Infection Control Committees of the Hospitals reported that they could give the annual incidence of VAP in the ICUs, data for the VAP rates in 2014 and 2015 were compared. However, since the diagnostic criteria for VAP changed in 2015 in one of the ICUs in the control group, the data for that VAP rate could not be used.

\section{Data analyses}

All analyses were performed using Statistical Package for the Social Sciences (SPSS, IBM Corp., IBM SPSS Statistics for Windows, Armonk, NY, USA), software package version 22.0. Frequencies, percentages, means, standard deviations, $t$-tests, Wilcoxon tests, and $\chi^{2}$ tests were used to evaluate the data. It was considered statistically significant when the twosided $p$ value was lower than .05 . The presence of a statistically significant difference between the groups in terms of continuous variables was examined with the Student's $t$-test for parametric variables. The analysis of non-normally distributed variables was performed using non-parametric methods. The Wilcoxon test was used to compare intergroup non-parametric ordinal variables. The $\chi^{2}$ test was used to assess whether there was a difference between the two groups.

\section{RESULTS}

\section{Demographics}

There was no statistically significant difference between the groups in terms of their features (age, gender, etc.), other than marital status $(p>.05)$. It was determined that the groups showed an equal distribution in terms of identifying characteristics (Table 1).

\section{Knowledge level}

Initially, the mean scores of the knowledge level were low in both groups $(14.050 \pm 2.295$ in the study group; $15.080 \pm 2.691$ in the control group). The mean scores at the last measurement in both groups were higher at a statistically significant level than the mean scores at the first measurement in both groups $(p<.05$; Table 2$)$, but the mean score at the last measurement in the study group was higher at a statistically significant level than the mean score at the last measurement in the control group ( $p<.05$; Table 2$)$.

The first and second post-training mean scores were higher at a statistically significant level than the first and second pre-training mean scores in the study group. Moreover, the last measurement mean score was lower at a statistically significant level than the second post-training mean score $(p<.05$; Table 3$)$. It was therefore determined that the level of knowledge increased significantly after each training session, and the level of knowledge decreased significantly in 6 months after each training session $(p<.05$; Table 3$)$.

\section{Preventive/reducing initiatives}

Initially, the total mean scores for all the initiatives were low in both groups $(40.133 \pm 5.147$ in the study group; $41.551 \pm$ 5.937 in the control group). At the first measurement, it was notably found that use of the closed aspiration system, aspiration of subglottic secretions, and use of mechanical ventilation (MV) weaning protocol initiatives were infrequently applied by both groups (Table 4).

At the last measurement, the mean scores for these three initiatives were statistically significantly higher than the initial scores in the study group; the mean score for the MV weaning initiative was also significantly higher in the control group $(p<.05)$. The total mean scores for all the initiatives at the last measurement in both groups were significantly higher than at the first measurement; however, there was no significant difference between the study and control groups $(p>.05$; Table 4$)$.

For the study group, the mean scores of nine initiatives at the last measurement were significantly higher than before the first training $(p<.05)$. The mean total scores at the last measurement were higher at a statistically significant level than the mean total scores before the first training $(p<.05)$. Moreover, it was seen that semi-recumbent positioning, oral care, the administration of normal saline during aspiration, and confirming feeding tube placement were at the desired level (Table 5).

\section{VAP incidence}

In both the study and control group ICUs, the mean VAP rate in 2014 was higher than it was in $2015(p<.05)$. Although the VAP rate was lower in the control group ICUs in 2014, it was lower in the study group ICUs in 2015 (Table 6).

\section{DISCUSSION}

This study was conducted to determine the effect of training given to nurses to reduce the VAP rate in adult ICUs. There was no statistically significant difference in descriptive characteristics between the study and control groups except for marital status. The number of married nurses was significantly higher in the study group, and the number of single nurses was significantly higher in the control group. However, the marital status of the nurses was not seen as a feature that could influence our research hypotheses positively or negatively.

Increasing ICU nurses' knowledge of VAP and implementation of evidence-based applications in the care environment are the effective way to prevent VAP [30]. In the literature, in studies where ICU nurses' knowledge of VAP prevention was evaluated, nurses' knowledge of VAP was reported to be inadequate $[17,22,31,32]$. In this study, the mean scores before the first training in the study group and the mean scores at the first measurement in the control group were found to be low on the VAP Information Test. This finding supports the findings of other studies. It can be concluded that ICU nurses are not aware of VAP prevention/reducing initiatives and that the lack of knowledge in this field should be eliminated.

It is clear that the knowledge and application levels of VAP initiatives by nurses can be increased with training [17, 19, 33-35]. In studies where training initiatives for preventing VAP were studied, the level of nurses' knowledge and awareness of VAP, and their compliance levels for 
Table 1. The distributions of the nurses in the study and control groups according to their descriptive characteristics

\begin{tabular}{|c|c|c|c|c|c|c|}
\hline \multirow[b]{3}{*}{ Features } & \multicolumn{4}{|c|}{ Groups } & \multirow[b]{3}{*}{$\chi^{2}$} & \multirow[b]{3}{*}{$p$} \\
\hline & \multicolumn{2}{|c|}{ Study group $(n=60)$} & \multicolumn{2}{|c|}{ Control group $(n=49)$} & & \\
\hline & $n$ & $\%$ & $n$ & $\%$ & & \\
\hline \multicolumn{7}{|l|}{ Age groups } \\
\hline$<25$ age & 13 & 21.7 & 14 & 28.6 & 0.690 & .406 \\
\hline$\geq 25$ age & 47 & 78.3 & 35 & 71.4 & & \\
\hline Mean $\pm S D$ & \multicolumn{2}{|c|}{$29.45 \pm 6.296$} & \multicolumn{2}{|c|}{$27.47 \pm 5.327$} & $t=1.779$ & .780 \\
\hline \multicolumn{7}{|l|}{ Gender } \\
\hline Female & 43 & 71.7 & 37 & 75.5 & 0.204 & .409 \\
\hline Male & 17 & 28.3 & 12 & 24.5 & & \\
\hline \multicolumn{7}{|l|}{ Marital status } \\
\hline Married & 31 & 51.7 & 8 & 16.3 & 14.660 & .000 \\
\hline Single & 29 & 48.3 & 41 & 83.7 & & \\
\hline \multicolumn{7}{|l|}{ Educational level } \\
\hline High school & 10 & 16.7 & 12 & 24.5 & 1.470 & .689 \\
\hline Associate degree & 6 & 10.0 & 4 & 8.2 & & \\
\hline Undergraduate education & 36 & 60.0 & 25 & 51.0 & & \\
\hline Graduate education & 8 & 13.3 & 8 & 16.3 & & \\
\hline \multicolumn{7}{|l|}{ Graduated program } \\
\hline Nursing & 47 & 78.3 & 40 & 81.6 & 12.275 & .092 \\
\hline Midwifery & 0 & 0.0 & 1 & 2.0 & & \\
\hline Emergency medical technician & 10 & 16.7 & 1 & 2.0 & & \\
\hline First and emergency aid & 2 & 3.3 & 1 & 2.0 & & \\
\hline Medical laboratory & 1 & 1.7 & 3 & 6.1 & & \\
\hline Hospital and medical institutions management & 0 & 0.0 & 1 & 2.0 & & \\
\hline Human resources management & 0 & 0.0 & 1 & 2.0 & & \\
\hline Health officer & 0 & 0.0 & 1 & 2.0 & & \\
\hline \multicolumn{7}{|l|}{ Professional experience } \\
\hline$<1$ year & 6 & 10.0 & 6 & 12.2 & 0.508 & .776 \\
\hline $1-9$ years & 43 & 71.7 & 32 & 65.3 & & \\
\hline$\geq 10$ years & 11 & 18.3 & 11 & 22.4 & & \\
\hline \multicolumn{7}{|l|}{ Working time in institution } \\
\hline$<1$ year & 18 & 30.0 & 12 & 24.5 & 2.897 & .235 \\
\hline $1-9$ years & 35 & 58.3 & 35 & 71.4 & & \\
\hline$\geq 10$ years & 7 & 11.7 & 2 & 4.1 & & \\
\hline \multicolumn{7}{|l|}{ ICU type } \\
\hline Anaesthesia and reanimation & 43 & 71.7 & 42 & 85.7 & 7.225 & .065 \\
\hline Neurology & 2 & 3.3 & 0 & 0.0 & & \\
\hline Emergency & 9 & 15.0 & 7 & 14.3 & & \\
\hline Post-operative & 6 & 10.0 & 0 & 0.0 & & \\
\hline \multicolumn{7}{|l|}{ ICU experience } \\
\hline$<1$ year & 11 & 18.3 & 8 & 16.3 & 4.745 & .093 \\
\hline $1-9$ years & 39 & 65.0 & 39 & 79.6 & & \\
\hline$\geq 10$ years & 10 & 16.7 & 2 & 4.1 & & \\
\hline \multicolumn{7}{|l|}{ Did you receive any training for $V A P$ ? } \\
\hline Yes & 25 & 41.7 & 23 & 46.9 & 0.304 & .360 \\
\hline No & 35 & 58.3 & 26 & 53.1 & & \\
\hline \multicolumn{7}{|c|}{ Do you think that VAP can be reduced with training? } \\
\hline Yes & 54 & 90.0 & 47 & 95.9 & 1.389 & .212 \\
\hline No & 6 & 10.0 & 2 & 4.1 & & \\
\hline
\end{tabular}

Note. Bold values represent statistically significant. $\chi^{2}$ : chi-square test; ICU: intensive care unit; VAP: ventilator-associated pneumonia.

the care bundle were increased, and the incidence of VAP was decreased $[3,16,18,26]$. It was determined in this study that the mean scores at the last measurement in the study and control groups were higher at a statistically significant level. Moreover, the post-training mean scores were higher than the pre-training mean scores on the VAP Information Test in the study group. It was found that there was a statistically significant decrease in the knowledge level of the nurses during 6 months between trainings (Table 2). There was a significant difference in favour of the study group in terms 
Table 2. The comparison of the mean scores at the first and last measurements on the VAP Information Test of the nurses in the study and control groups

\begin{tabular}{|c|c|c|c|c|}
\hline \multirow[b]{3}{*}{ Initiatives } & \multicolumn{2}{|l|}{ Groups } & \multirow[b]{3}{*}{$t^{*}$} & \multirow[b]{3}{*}{$p$} \\
\hline & Study group (before first training; $n=60$ ) & Control group $(n=49)$ & & \\
\hline & $\bar{x} \pm S D$ & $\bar{x} \pm S D$ & & \\
\hline First measurement & $14.050 \pm 2.295$ & $15.080 \pm 2.691$ & -2.160 & .033 \\
\hline Last measurement & $17.820 \pm 1.444$ & $16.100 \pm 2.136$ & 4.956 & .000 \\
\hline Test $\left(t^{* * / p}\right.$ value $)$ & $-12.475 / .000$ & $-3.190 / .003$ & & \\
\hline
\end{tabular}

Note. Bold values represent statistically significant. VAP: ventilator-associated pneumonia; $S D$ : standard deviation.

$* t$-test between groups at each measurement (independent samples $t$-test). ${ }^{* *} t$-test between measurements in the groups (paired-samples $t$-test).

Table 3. The comparison of the mean scores of the VAP Information Test at the first, second, and last trainings of the nurses in the study group $(n=60)$

\begin{tabular}{|c|c|c|c|c|}
\hline Training time & Mean & $S D$ & $t$ & $p$ \\
\hline Before first training & 14.050 & 2.295 & \multirow[t]{2}{*}{-12.026} & \multirow[t]{2}{*}{.000} \\
\hline After first training & 17.670 & 1.526 & & \\
\hline After first training & 17.670 & 1.526 & \multirow[t]{2}{*}{5.264} & \multirow[t]{2}{*}{.000} \\
\hline Before second training & 16.270 & 1.876 & & \\
\hline Before second training & 16.270 & 1.876 & \multirow[t]{2}{*}{-10.863} & \multirow[t]{2}{*}{.000} \\
\hline After second training & 18.600 & 1.061 & & \\
\hline After second training & 18.600 & 1.061 & \multirow[t]{2}{*}{4.023} & \multirow[t]{2}{*}{.000} \\
\hline Last measurement & 17.820 & 1.444 & & \\
\hline Before first training & 14.050 & 2.295 & \multirow[t]{2}{*}{-12.475} & \multirow[t]{2}{*}{.000} \\
\hline Last measurement & 17.820 & 1.444 & & \\
\hline
\end{tabular}

Note. Bold values represent statistically significant. VAP: ventilator-associated pneumonia; $S D$ : standard deviation; $t$ : $t$-test between groups (independent samples $t$-test).

of the effectiveness of the training given for preventing VAP. This supports the results of previous studies reporting that training was important and effective in increasing the knowledge levels of nurses on VAP and also it confirms our H1 hypothesis. However, the findings that show a decrease in the knowledge level of the nurses on the VAP Information Test during 6 months between trainings can be interpreted as that the training given to nurses for VAP should be repeated at least every 6 months. The increase in the mean scores of the control group gives the impression that the applied information test creates awareness and therefore nurses try to learn by themselves.

It has been reported that VAP incidence can be reduced by $20 \%$ with basic and appropriate infection control measures [14, 24, 27, 36]. However, it was found in the study conducted on nurses by Bagheri-Nesami et al. [33] that the implementation of all preventive/reducing initiatives was rather low. In studies where the effect of the training given to nurses on the implementation levels of VAP preventive initiatives was examined, it was shown that the implementation levels of these initiatives were increased at a statistically significant level in nurses [21, 37, 38]. In this study, of nurses in the study group, the mean scores of the implementation of nine initiatives were increased at a statistically significant level at the last measurement compared to implementation scores before the first training. However, it was found that a closed aspiration system was used at a low rate. In the study group, the mean scores of the implementation of three initiatives were increased at the last measurement. In this study, the obtained data on the increase in the implementation levels of VAP preventive/reducing nursing initiatives in both groups (especially in the study group) support literature data. However, the difference between the groups was not statistically significant and the H2 hypothesis was rejected.

It is reported that the use of the closed aspiration method is important in preventing/reducing VAP. However, the vast majority of the nurses used an open aspiration system at the beginning of our study. As Ozden [39] has stated, this result can be caused by the difficulty in manipulating the catheter of a closed system. With an open system, however, the secretions cannot be aspirated enough. Moreover, it is emphasized that a closed system is less risky than an open aspiration system in terms of preservation of the hemodynamic balance of the patient, cost reduction, and VAP development. It can be said that informing nurses about the benefits of the closed aspiration method and encouraging them to use it are necessary and important.

We saw an increase in the implementation levels of VAP preventive/reducing initiatives in the control group. It is believed that this was caused by the increased awareness level on the subject because they knew that the tests applied in the study would be reapplied later, and they directed themselves to read and do research to get a higher score on the next test. The trained nurses in the ICUs also may have behaved more carefully and directed other nurses. 


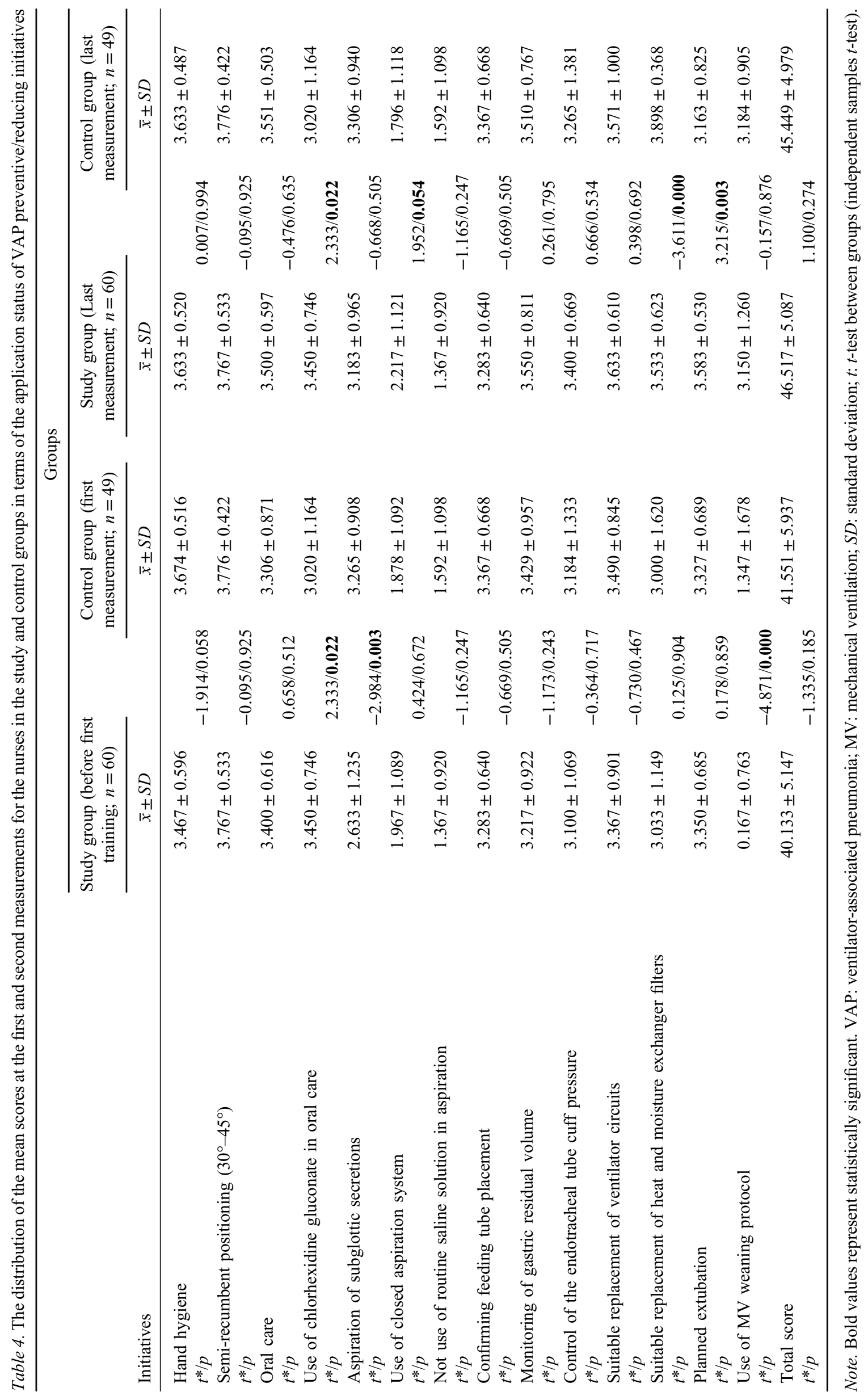




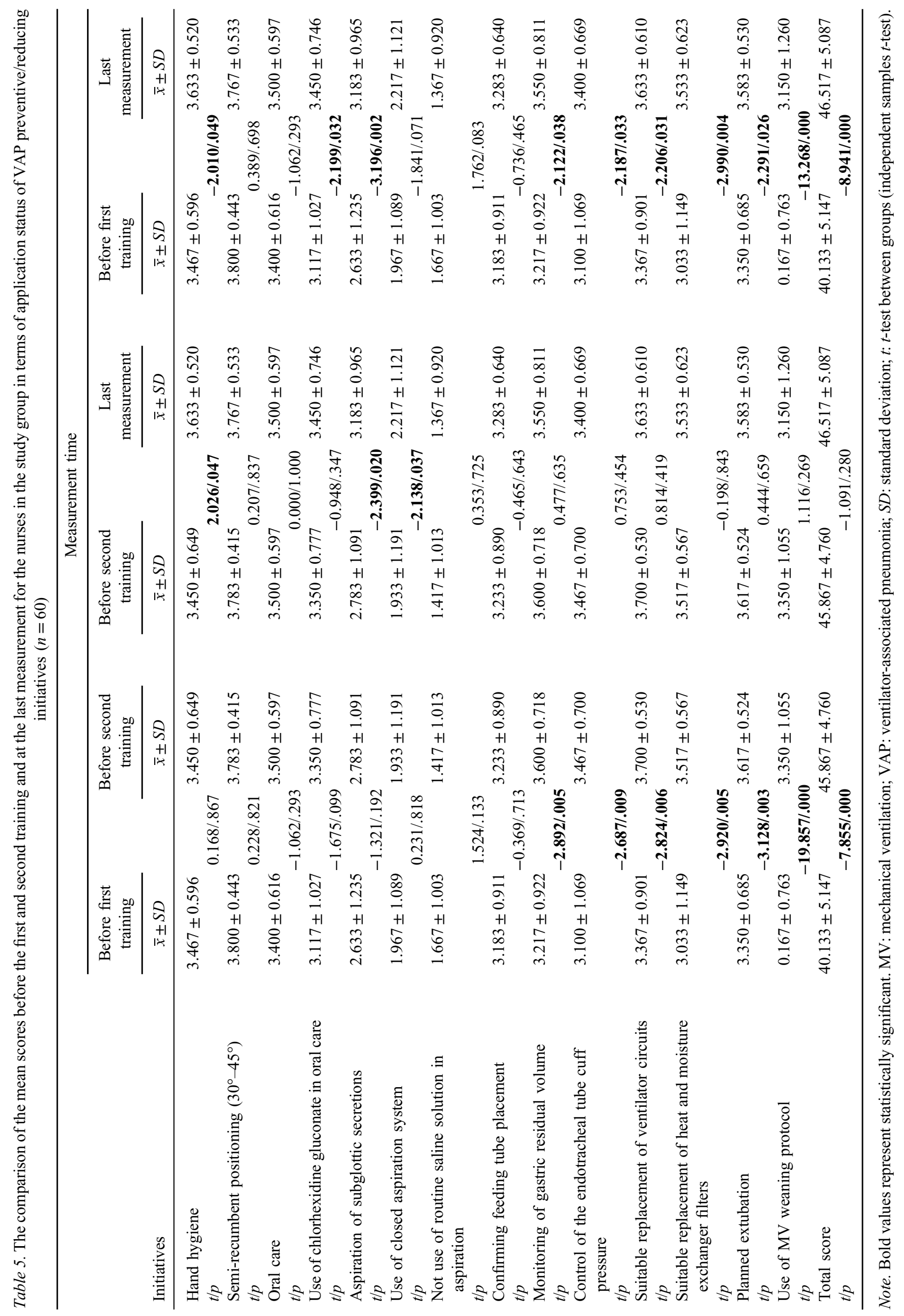


Table 6. The mean VAP rate for 2014 and 2015 in the ICUs in the study and control groups

\begin{tabular}{|c|c|c|c|c|c|c|c|}
\hline \multicolumn{8}{|c|}{ VAP rate } \\
\hline \multirow[b]{3}{*}{ Groups } & \multirow[b]{3}{*}{$N$} & \multicolumn{4}{|c|}{ Year } & \multirow[b]{3}{*}{$Z^{*}$} & \multirow[b]{3}{*}{$p$} \\
\hline & & \multicolumn{2}{|c|}{2014} & \multicolumn{2}{|c|}{2015} & & \\
\hline & & Mean & $S D$ & Mean & $S D$ & & \\
\hline Study group & 6 & 12.856 & 6.538 & 6.866 & 1.769 & & \\
\hline Control group** & 2 & 10.885 & 0.162 & 8.280 & 1.626 & & \\
\hline Total & 8 & 12.364 & 5.601 & 7.220 & 1.744 & -2.100 & .036 \\
\hline
\end{tabular}

Note. VAP: ventilator-associated pneumonia; ICU: intensive care unit; $S D$ : standard deviation.

*The Wilcoxon test. **Since the diagnostic criteria for VAP changed in 2015 in one ICU in the control group, the data for VAP rate could not be used.

Because there are multiple risk factors leading to VAP and because many factors are closely related to nursing initiatives, the training given to nurses can reduce the incidence of VAP by about $50 \%[33,34,36]$. In several studies of the effect of training given to nurses for preventing VAP on the incidence of VAP, it was found that the incidence of VAP was decreased at a statistically significant level $[24,33,34]$. In one study, the effect of training given to ICU staff in short sessions on the VAP rate was a non-significant reduction, but it was suggested that the non-significance may have been due to the lack of infrastructure, such as surveillance monitoring and a very high turnover rate in nurses [23].

In this study, although the VAP rate was lower in the ICUs in the control group than in the ICUs in the study group in 2014, the VAP rate was lower in the ICUs in the study group than in the ICUs in the control group in 2015 (Table 6). One of the VAP preventive/reducing nursing initiatives is the training of the health staff. In this context, awareness is created in nurses through training, and it may therefore be possible to increase the knowledge level of VAP and to implement evidence-based practices. In addition to the study group, the decrease in the incidence of VAP in the control group is also remarkable. One of the important indicators of healthcare quality in ICUs is the incidence of VAP. Therefore, it could be that the study attracted considerable attention in the nurses working in the ICUs. This result suggests that the nurses really responded to the tests with great interest and curiosity. The awareness of the institution of VAP might also have been increased by this study. In this context, it can be considered possible that the institutions developed improved monitoring and applications related to VAP within the year of the study. According to the result obtained from this study, it can be stated that the incidence of VAP in the ICUs can be reduced by providing training to nurses once in every 6 months. This result supports the finding of other studies in which it was reported that the training given to nurses reduced the incidence of VAP. It also confirms our H3 hypothesis.

\section{CONCLUSIONS}

Intensive care nurses who are primarily responsible for patient care play an important role in preventing the development of VAP in ICUs. The knowledge and application levels of VAP initiatives and evidence-based strategies for preventing VAP are low for the majority of nurses. This shows that nurses need special training and qualification in ICU nursing. It can be suggested that ICU administrators use a checklist, which includes the Preventive/Reducing Initiatives of VAP, and the practical training of nurses at least every 6 months (to ensure standardized care such as aspiration of subglottic secretions and control of the endotracheal tube cuff pressure) to reduce the incidence of VAP.

Acknowledgements: The authors would like to thank all the intensive care unit workers, especially nurses who participated in this study, and the head nurses who participated in data collection.

Authors' contribution: HOC contributed to the conception and study design, data collection, data analysis, manuscript preparation, and final approval of the version to be submitted. NK contributed to the study design, data analysis, manuscript preparation, drafting the article, and revising it critically for important intellectual content. The final approved version is submitted.

Ethical approval: The study was approved by the Clinical Research Ethics Committee of Bezmialem Vakif University (Date/Number: 28.11.2014/71306642-050.01.04). Institutional permission was also received from nine hospitals. After the study was completed, the nurses in the control group were also trained.

Conflicts of Interest/Funding: The authors declare no conflicts of interest. No financial support was received for this study.

\section{REFERENCES}

1. Sosa-Hernandez O, Matías-Tellez B, Estrada-Hernandez A, Cureno-Díaz MA, Bello-Lopez JM. Incidence and costs of ventilator-associated pneumonia in the adult intensive care 
unit of a tertiary referral hospital in Mexico. Am J Infect Control. 2019;47(9):e21-e25.

2. Alja' afreh MA, Mosleh SM, Habashneh SS. The effects of oral care protocol on the incidence of ventilation-associated pneumonia in selected intensive care units in Jordan. Dimens Crit Care Nurs. 2019;38(1):5-12.

3. Subramanian P, Choy KL, Gobal SV, Mansor M, Ng KH. Impact of education on ventilator-associated pneumonia in the intensive care unit. Singapore Med J. 2013;54(5):281-4.

4. Hunter JD. Ventilator associated pneumonia. BMJ. 2012;344:40-4.

5. Jansson MM, Syrjälä HP, Ala-Kokko TI. Association of nurse staffing and nursing workload with ventilator-associated pneumonia and mortality: a prospective, single-center cohort study. J Hosp Infect. 2019;101:257-63.

6. Afhami S, Seifi A, Hajiabdolbaghi M, et al. Assessment of device-associated infection rates in teaching hospitals in Islamic Republic of Iran. East Mediterr Health J. 2019;25(2):90-7.

7. Viet Hung N, Hang PT, Rosenthal VD, et al. Multicenter study of device-associated infection rates, bacterial resistance, length of stay, and mortality in intensive care units of 2 cities of Vietnam: International Nosocomial Infection Control Consortium findings. J Patient Saf. 2018;1-6. doi:10.1097/ PTS.0000000000000499

8. Yilmaz G, Aydin H, Aydin M, Saylan S, Ulusoy H, Koksal I. Staff education aimed at reducing ventilator associated pneumonia. J Med Microbiol. 2016;65:1378-84.

9. Samrah S, Bashtawi Y, Havaineh W, Almomani B, Momany S, Khader Y. Impact of colistin-initiation delay on mortality of ventilator-associated pneumonia caused by $A$. baumannii. J Infect Dev Ctries. 2016;10(10):1129-34.

10. Tağrıkulu H, Memiş D, nal MT, Turan N. Investigation of ventilator associated pneumoniae in intensive care patients. $\mathrm{J}$ Turk Soc Intens Care. 2016;14:28-38.

11. Karatas M, Saylan S, Kostakoglu U, Yilmaz G. An assessment of ventilator-associated pneumonias and risk factors identified in the intensive care unit. Pak J Med Sci. 2016;32(4):817-22.

12. Yelken B, Memis D, Durmaz G, Yosunkaya A, Aygun G. VentilatorleIliskiliPnomonideTaniveTedaviRehberi. [Diagnosis and treatment guide for ventilator-associated pneumonia]. In: F. Kahveci, ed. Turk Yogun Bakiim Dernegi Dergisi [Turkish Journal of Intensive Care Society]. Istanbul: Ozgun Ofset; 2011. p. 1-28.

13. Tomak Y, Erturk A, Sen A, Erdivanli B, Kurt A. Ventilatorassociated pneumonia rate and causative microorganisms in an anesthesia intensive care unit. Med Bull Sisli Etfal Hosp. 2012;46(3):115-9.

14. Donmez NF, Kanyilmaz D, Tiryaki C, Yilmaz S, Dikmen B. Evidence-based guidelines for the prevention of ventilator associated pneumonia: Results of knowledge test among anesthesia residents employed in ICU. Turk J Anaesthesiol Reanim. 2012;40(4):202-11.

15. Saltoglu N. Ventilator iliskili pnomoninin onlenmesi ve kontrolu [Prevention and control for ventilator-associated pneumonia] [Internet]. In Hastane Enfeksiyonlari: Korunma ve control. Sempozyum Dizisi No:60 Ocak 2008; s89-103 [Hospital Infections: Protection and Control. Symposium Series No. 60, January 2008, s89-103]. [cited 2019 June 22]. Available from http://www.ctf.edu.tr/stek/pdfs/60/ 6010.pdf. (in Turkish)
16. Aloush SM, Abdelkader FA, Tawalbeh LI, Bashtawy MA. Compliance of nurses and hospitals with ventilator-associated pneumonia prevention guidelines: a Middle Eastern survey. Nurs Care Qual. 2018;33(3):8-14.

17. Maurya S, Mishra SB, Azim A, Baronia AK, Gurjar M. Ventilator-associated complications: a study to evaluate the effectiveness of a planned teaching program for intensive care unit staff nurses-an Indian experience. Am J Infect Control. 2016;44(11):1422-3.

18. Hassan ZM, Wahsheh MA. Knowledge level of nurses in Jordan on ventilator-associated pneumonia and preventive measures. J Evid Based Med. 2019;12(1):16-21.

19. Akinci C, Cakar N, Ayyildiz A, Atalan HK, Ayyildiz A. To evaluate the knowledge of intensive care nurses about the prevention of ventilator-associated pneumonia. Turk J Anaesthesiol Reanim. 2010;38(1):45-51.

20. Cetinkaya Sardan Y. Infeksiyon Kontrolunde Paketler [Bundles in infection control]. Yogun Bakiim Dergisi [Turkish Journal of Intensive Care Medicine]. 2010;9(4):188-92.

21. Bouadma L, Mourvillier B, Deiler V, et al. A multifaceted program to prevent ventilator-associated pneumonia: impact on compliance with preventive measures. Crit Care Med. 2010;38:789-96.

22. Jansson M, Ala-Kokko $T$, Ylipalosaari $P$, Syrjälä $H$, Kyngäs H. Critical care nurses' knowledge of, adherence to and barriers towards evidence-based guidelines for the prevention of ventilator-associated pneumonia - a survey study. Intensive Crit Care Nurs. 2013;29(4):216-27.

23. Khan MS, Siddiqui SZ, Haider S, et al. Infection control education: impact on ventilator-associated pneumonia rates in a public sector intensive care unit in Pakistan. Trans R Soc Trop Med Hyg. 2009;103(8):807-11.

24. Lerma FÁ, García MS, Lorente L, et al. Guidelines for the prevention of ventilator-associated pneumonia and their implementation: the Spanish "Zero-VAP" bundle. Med Intensiva. 2014;38(4):226-36.

25. Ozgur ES, Horasan ES, Karaca K, Ersoz G, Atis SN, Kaya A. Ventilator-associated pneumonia due to extensive drug-resistant Acinetobacter baumannii: risk factors, clinical features, and outcomes. Am J Infect Control. 2014;42:206-8.

26. Jansson $M$, Kääriäinen $M$, Kyngäs $H$. Effectiveness of educational programmes in preventing ventilator-associated pneumonia: a systematic review. J Hosp Infect. 2013;84: 206-14.

27. Leblebicioglu H, Yalcin AN, Rosenthal VD, et al. Effectiveness of a multidimensional approach for prevention of ventilator-associated pneumonia in 11 adult intensive care units from 10 cities of turkey: findings of the International Nosocomial Infection Control Consortium (INICC). Infection. 2013;41(2):447-56.

28. Rosenthal VD, Rodrigues C, Álvarez-Moreno C, et al. Effectiveness of a multidimensional approach for prevention of ventilator-associated pneumonia in adult intensive care units from 14 developing countries of four continents: findings of the International Nosocomial Infection Control Consortium. Crit Care Med. 2012;40(12):3121-8.

29. Tablan OC, Anderson LJ, Besser R, et al. Guidelines for preventing health-care-associated pneumonia, 2003: recommendations of CDC and the Healthcare Infection Control Practices Advisory Committee. MMWR Recomm Rep. 2004;53(RR-3):1-36. 
30. Akin Korhan E, Hakverdioglu Yont G, Parlar Kilic S, Uzelli D. Knowledge levels of intensive care nurses on prevention of ventilator-associated pneumonia. Nurs Crit Care. 2014;19(1):26-33.

31. Al-Sayaghi KM. Prevention of ventilator-associated pneumonia: a knowledge survey among intensive care nurses in Yemen. Saudi Med J. 2014;35(3):269-76.

32. Labeau S, Vandijck D, Rello J, et al. Evidence-based guidelines for the prevention of ventilator associated pneumonia: Results of a knowledge test among European intensive care nurses. J Hosp Infect. 2008;70(2):180-5.

33. Bagheri-Nesami M, Amiri-Abchuyeh M, GholipourBaradari A, Yazdani-Cherati J, Nikkhah A. Assessment of critical care provider's application of preventive measures for ventilator-associated pneumonia in intensive care units. J Clin Diagn Res. 2015;9(8):IC05-08.

34. Khezri HD, Zeydi AE, Firouzian A, et al. The Importance of oral hygiene in prevention of ventilator-associated pneumonia (VAP): a literature review. Int J Caring Sci 2014;7(1):12-23.

35. McHugh SM, Hill AD, Humphreys H. Preventing healthcareassociated infection through education: have surgeons been overlooked? Surgeon. 2010;8(2):96-100.

36. Coffin SE, Klompas M, Classen D, et al. Strategies to prevent ventilator-associated pneumonia in acute care hospitals. Infect Control Hosp Epidemiol. 2008;29(1):S31-40.

37 Lim KP, Kuo SW, Ko WJ, et al. Efficacy of ventilator-associated pneumonia care bundle for prevention of ventilator-associated pneumonia in the surgical intensive care units of a medical center. J Microbiol Immunol Infect. 2015;48(3):316-21.

38 Cutler LR, Sluman P. Reducing ventilator associated pneumonia in adult patients through high standards of oral care: a historical control study. Intensive Crit Care Nurs. 2014;30(2):61-8.

39. Ozden D. Kapali sistem aspirasyon yontemi [Method of closed system suctioning]. Hemsirelik Yuksekokulu Dergisi [Journal of Nursing]. 2007;11(3):29-37. 